\title{
Efficiency of dual-energy computed tomography enterography in the diagnosis of Crohn's disease
}

Jinghao Chen ${ }^{1 \dagger}$, Jie Zhou ${ }^{1,2 \dagger}{ }^{\text {, Jushun Yang }}{ }^{1}$, Ruochen Cong ${ }^{1}$, Jinjie Sun ${ }^{3}$, Jing Xiao ${ }^{4}$, Jianhua Shi ${ }^{5}$ and Bosheng $\mathrm{He}^{1,6^{*}}$

\begin{abstract}
Background: This retrospective study aimed to investigate the usefulness of the optimized kiloelectron volt (keV) for virtual monoenergetic imaging (VMI) combined with iodine map in dual-energy computed tomography enterography (DECTE) in the diagnosis of Crohn's disease (CD).

Methods: Seventy-two patients (mean age: $41.89 \pm 17.28$ years) with negative computed tomography enterography (CTE) were enrolled for investigating the optimized VMI keV in DECTE by comparing subjective and objective parameters of VMls that were reconstructed from 40 to $90 \mathrm{keV}$. Moreover, 68 patients (38.27 \pm 15.10 years; 35 normal and 33 CD) were included for evaluating the diagnostic efficacy of DECTE iodine map at the optimized VMI energy level and routine CTE for CD and active CD. Statistical analysis for all data was conducted.

Results: Objective and subjective imaging evaluations showed the best results at $60 \mathrm{keV}$ for VMls. The CT values of the normal group, active subgroup, and CD group during the small intestinal phase at routine $120 \mathrm{kVp}$ or $60 \mathrm{keVVMI}$ had significant differences. The diagnostic efficacy of an iodine map was the best when NIC $=4 \%$ or fat value $=45.8 \%$ for $C D$, whereas $\mathrm{NIC}<0.35$ or the fat value $<0.38$ for active CD. The combined routine CTE and optimized VMI improved the diagnostic efficacy $(P<0.001)$.
\end{abstract}

Conclusions: VMI at $60 \mathrm{keV}$ provided the best imaging quality on DECTE. NIC and fat value provided important basis for active CD evaluation. Routine CTE combined with VMI at $60 \mathrm{keV}$ improved the diagnostic efficiency for CD.

Keywords: Crohn's disease, Virtual monoenergetic imaging, lodine map, Dual energy CT, CT enterography

\section{Background}

Crohn's disease $(\mathrm{CD})$, one of the two main subtypes of inflammatory bowel disease (IBD), frequently and transmurally affects any segment of the digestive tract, particularly the walls of the terminal ileum and adjacent colon. The pathogenesis of $\mathrm{CD}$ remains unclear, and may be caused by multiple factors such as the environment,

\footnotetext{
*Correspondence: boshenghe@126.com

${ }^{\dagger}$ Jinghao Chen and Jie Zhou have contributed equally to this work.

1 Department of Radiology, Affiliated Hospital 2 of Nantong University,

Nantong City 226001, Jiangsu Province, China

Full list of author information is available at the end of the article
}

heredity, colonic microorganisms, the immune system, as well as other yet-unknown ones [1]. The prevalence of $C D$ in China has increased in recent years owing to a change in diet [2]. The pathological characteristics of $\mathrm{CD}$ are identified by thickened walls and lumen stenosis of the intestine [3]. Moreover, because CD often presents itself through recurrence and remission over the lifetime of a patient, an assessment of the illness conditions is essential for diagnosis, treatment, and prognosis [4].

Standard measurements used in imaging examinations have been proposed to evaluate the activities of $\mathrm{CD}$ patients. Owing to the inconvenience and invasiveness of 
endoscopy, multi-slice computed tomography enterography (MSCTE), which is less expensive than magnetic resonance enterography, has become a popular and suitable way for a routine monitoring in CD patients [5-7]. Although the extent of the enhancements in the field of MSCTE has been closely connected with CD activities, there are many overlaps between the imaging characteristics of $C D$ and other abdominal lesions [8-10]. In addition, intramural fat may cover some signs visible from an MSCTE, or the site of a hemorrhage may confuse the enhancement of MSCTE [11]. To avoid a misdiagnosis of $C D$, a distinguishable and clear image of the lesions is essential for a fast and accurate diagnosis.

Dual-energy CT (DECT) is an imaging technique based on data acquisition at two different energy settings, which can be used to diagnose lesions with higher quality and a more accurate quantity compared with a routine CT [12]. Dual-energy CT enterography (DECTE) is confirmed to have prominent ability to recognize the intestinal wall [13]. DECTE can not only obtain an imaging quality and diagnostic efficiency similar to that obtained in a routine CT $[14,15]$, but also significantly reduced both the radiation dose and number of CT scans $[16,17]$, offering unique advantages in the diagnosis and evaluation of activities in CD patients, especially young patients. DECTE can be used to not only quantitatively evaluate the degree of inflammation through the absolute iodine value (iodine map) of the enhancement based on an energy spectrum purification in an intestine with $C D$, but also improve the image contrast of normal blood supply vessels using virtual monochromatic imagings (VMIs) to clearly depict the boundary between an inflamed intestine and normal intestinal tissue [18]. DECTE can also clearly display the proliferative small vessels below grade 4 in low $\mathrm{keV}$ images and iodine maps, and they can be easily differentiated from the superior mesenteric artery (SMA) with an improved diagnostic efficiency [15]. Darras et al. showed the advantages and accuracy of using DECT in an intestinal obstruction study [19]. However, the diagnostic value of DECTE in CD has not been fully clarified.

In this retrospective study, we performed VMI reconstruction at several different energies and investigated the optimized kiloelectron volt (keV) for VMIs in DECTE. Then, we retrospectively explored the significance of the optimized $\mathrm{keV}$ of VMIs combined with iodine map in DECTE for an evaluation of the intestinal walls and vessels of patients with $\mathrm{CD}$. Furthermore, the diagnostic efficacy of iodine maps for $\mathrm{CD}$ and active $\mathrm{CD}$ was analyzed, and that of DECTE + VMIs and a routine CTE was compared. A flowchart of our study is shown in Additional file 1: Figure S1. Our findings will provide a theoretical basis for improved diagnosis of $\mathrm{CD}$.

\section{Methods}

This study was approved by the Ethics Committee of Affiliated Hospital 2 of Nantong University (2019KW022), and the requirement to obtain informed written consent was waived. All methods were carried out in accordance with relevant guidelines and regulations.

\section{Patients}

In a study on the optimized $\mathrm{keV}$ of VMI, the clinical and imaging data of 220 patients with DECTE in our hospital were collected from July 2018 to January 2019. The inclusion criteria of this study were as follows: (1) patients with a normal small intestine as verified through an endoscopy and complete clinical data; (2) patients with normal liver and kidney function, and without an allergy history of iodine or contraindications of contrast medium; (3) patients who underwent a DECTE test; and (4) patients with an intestinal filling score greater than 3 . The intestinal filling score was defined as previous described [20, 21]. Finally, 72 patients (40 males and 32 females) ranging from 19 to 76 years old with an average age of $41.89 \pm 17.28$ met the inclusion criteria.

For an evaluation of the diagnostic efficacy of DECTE iodine map at the optimized VMI energy level and routine CTE for CD, we collected the clinical and imaging data of 92 patients staying in our hospital from June 2018 to December 2019, with a suspected disease in their small intestine. The inclusion criteria were the same as in the above study. However, the exclusion criteria of this study were as follows: (1) patients below 18 years of age; (2) patients with a pregnancy or serious underlying disease; (3) patients with an allergy history of iodine; and (4) patients with liver or kidney dysfunction. In addition, a total of 24 patients did not meet the inclusion or exclusion criteria. There were 12 patients without DECT data, 8 patients without complete clinical data, and 4 patients with a severe underlying disease. Finally, 68 patients were enrolled in the study, including 35 patients who were confirmed as having a normal small intestine through a close follow-up and 33 patients who were diagnosed as having CD based on endoscopy or previous pathology.

\section{DECTE}

The patients were asked to avoid food for 4 or $8 \mathrm{~h}$ prior to the examination. Before preparing the intestinal filling, it was necessary to determine whether there were contraindications of the intestinal filling. One hour before the DECTE, those without contraindications, including intestinal obstruction or poor tolerance for isotonic mannitol were orally administrated with $2000 \mathrm{ml}$ of $2.5 \%$ isotonic mannitol at an interval of 15 min (approximately $500 \mathrm{ml}$ each time). Ten minutes before DECTE, those without contraindications for anisodamine (e.g. 
increased intracranial pressure and acute cerebral hemorrhage; glaucoma; prostatic hypertrophy; fresh fundus hemorrhage; malignant tumors; and pregnancy) were intramuscularly injected with $10 \mathrm{mg}$ of per dose, prior to examination, to enhance the effect of the intestinal filling.

All CT examinations were performed through a dualsource DE unit (Somatom Force, Siemens Healthcare, Forchheim, Germany). A DECTE scan of each patient from the top of the diaphragm to the pubic symphysis was conducted. As the scanning parameters, a ball tube with tumor voltage of $90 \mathrm{kVp}$ and tube current of 230 $\mathrm{mAs}$, another ball tube with tube voltage of $\mathrm{Sn} 150 \mathrm{kVp}$ and tube current of $90 \mathrm{mAs}$, a fusion coefficient of 0.7 , a pitch of 0.9 , a slice thickness of $1 \mathrm{~mm}$, and a slice spacing of $1 \mathrm{~mm}$ were applied [12]. First, a plain scan was conducted, and iopramine was injected into the anterior vein of the right elbow (at a concentration of $350 \mathrm{mg} / \mathrm{ml}$ ). The scanning was auto-started at the arterial phase once the abdominal aorta arrived at the threshold $(100 \mathrm{Hu})$, or at small intestine phase (approximately $40 \mathrm{~s}$ after injection), or at the venous phase (approximately $75 \mathrm{~s}$ after injection). All patients underwent CT scanning at all three phases.

\section{Image reconstruction}

The SMA was evaluated through images of the arterial phase, and the original data were transferred to a Siemens Syngovia post-processing workstation. The images were reconstructed on the coronal plane of the SMA, with the maximum intensity projection (MIP) parallel to the trunk of the SMA (the thickness of the slice was $10.0 \mathrm{~mm}$ and the interval between slices was $5.0 \mathrm{~mm}$ ), and a new single-energy software (Dual Energy Monoenergetic Plus, Mono +, Siemens Healthcare, Forchheim, Germany) was used to reconstruct the MIP images at $40-90 \mathrm{keV}$ with increments of $10 \mathrm{keV}$ and six groups of VMIs (Additional file 2: Figure S2). At the same time, a group of images at $120 \mathrm{kVp}$ were obtained, which were the mixed images reconstructed with a linear fusion coefficient of 0.7 from the $90 \mathrm{kVp}$ image scanned by a tube of dual-energy CT and the $\mathrm{Sn} 150 \mathrm{kVp}$ image scanned by another tube using Dual Energy Vascular.

The intestinal wall was evaluated using routine coronal images of the small intestine for a post-processing analysis of a multi-planar reformation (MPR) reconstruction. For the ileum at a distance of $1-5 \mathrm{~cm}$ of ileocecal (the thickness of the slice was $3.0 \mathrm{~mm}$ and the interval between slices was $3.0 \mathrm{~mm}$ ), a set of routine images at $120 \mathrm{kVp}$, and six groups of VMIs were reconstructed using post-processing software (Additional file 3: Figure S3).

The diseased intestinal wall was evaluated using images taken at the intestinal phase, and the original dual energy data were transferred to Siemens Sygovia post-processing workstations. Routine coronal images were processed through an MPR reconstruction (the thickness of the slice was $3.0 \mathrm{~mm}$, and the interval between slices was $3.0 \mathrm{~mm}$ ) at $60 \mathrm{keV}$. In addition, the coronal plane of the SMA images was processed as an MPI reconstruction (the thickness of the slice was $10.0 \mathrm{~mm}$, the interval between slices was $5.0 \mathrm{~mm}$ ) at $60 \mathrm{keV}$. The two VMIs of the diseased intestinal wall and the SMA on the DECTE were adjusted to $100 \%$ using liver nailfold videocapillaroscopy (NVC) to obtain the complete iodine maps [12].

\section{Objective analysis of images}

After the original images were magnified by three times, the region of interest (ROI) in the images was selected to avoid plaque and calcification affecting the measurements. The ROI was placed at the beginning of the SMA (area of $0.1 \mathrm{~cm}^{2}$ ) and gluteus maximus (area of $0.3 \mathrm{~cm}^{2}$ ). The CT values and noises with standard deviation (SD) were measured. For each measurement, the average values of three slices were obtained from the adjacent upper and lower slices to reduce the error. We then measured these magnified images again a week later. The calculated formulas of the signal-to-noise-ratio (SNR) and contrast-to-noise-ratio (CNR) were as follows: SNR $($ blood vessel $)=$ vascular CT/SD value; CNR (blood vessel $)=($ vascular $C$ T value - CT value of gluteus maximus muscle)/SD value of gluteus maximus muscle [22]; SNR (intestine) $=$ intestinal $\mathrm{CT} / \mathrm{SD}$ value; and CNR (intestine $)=($ intestinal $C T$ value-CT value of gluteus maximus)/SD value of gluteus maximus muscle [22].

In the overall iodine maps, which were used as references for the endoscopy and clinical diagnosis, the ROI was selected at the thickest level of the diseased intestinal wall for measuring the absolute iodine value and fat value, and selected at the bifurcation of abdominal aorta and iliac vessels for measuring the iodine value as much as possible. The ROI was set as a circle covering approximately $60-90 \%$ of the diseased intestinal wall. When the enhancements of the images between slices are different, the ROI selection should avoid the region with different enhancements in the images. Moreover, it was better to set the ROI in the obvious lesion of the transverse and coronal directions at the mesenteric side and avoid the necrosis, calcification, and vessels. Compared with the control measurement of the normal intestinal wall, every index was measured at different directions and slices three times [23].

The calculated formula of the normalized iodine concentration (NIC) was as follows: NIC $(\mathrm{mg} / \mathrm{ml})=$ intestinal wall iodine concentration/iodine concentration near the iliac bifurcation of the abdominal aorta [23]. 


\section{Subjective image analysis}

Images of SMA and its branches and intestinal wall were mainly observed. For the quantitative scores of blood vessel images, a five-component table [11] was used (Additional file 5: Table S1). To measure the grades of the blood vessels, we utilized an artificial intelligence (AI) model test through a constructed U-net model to segregate the SMA, and obtained images that clearly show the continuous blood vessels and the semi-automatically quantified grades of the SMA. Meanwhile, this study is mainly focused on images of vascular branches at Grade 4 and below (Additional file 4: Figure S4). According to the European CT Image Quality guidelines [24], the standard evaluation criteria for the subjective imaging quality and noise of the SMA and intestinal wall are shown in (Additional file 5: Table S2).

According to the latest expert consensus and references [25], the diagnostic criteria of the DECTE imaging evaluation for $\mathrm{CD}$ are as follows: intestinal wall thickening, intestinal wall enhancement and stratification, a mesenteric lymph node (MLN) enlargement, mesenteric exudation, straight small vessel hyperplasia (straight comb sign), at least three positive characteristic imaging signs of intestinal obstruction, peripheral abscess, fistula, and ascites. The quantitative parameters of DECTE images for evaluating the activity of $C D$ are listed [26] in Additional file 5: Table S3. The intestinal images of a routine CTE at $120 \mathrm{kVp}$ and DECTE + VMI at $60 \mathrm{keV}$ using an iodine map were evaluated by two radiologists with 10 and 5 years of experience, respectively, who were blinded to the imaging parameters, clinical materials, and first pathological results. The two radiologists subjectively evaluated the imaging characteristics of the intestinal and extra-intestinal lesions and complications. Disagreements in the imaging evaluation between two radiologists were resolved by consensus.

The reconstructed images of the SMA and intestinal wall were double-blindly evaluated by two observers who were radiologists with 3 and 5 years of experience for imaging evaluation, respectively, who independently scored the images. The consistency between the two radiologists was evaluated based on an intraclass correlation coefficient (ICC) [12]. An ICC value of $<0.20$ was considered to show poor confidence; $0.21-0.40$, slight confidence; $0.41-0.60$, moderate confidence; $0.61-0.80$, high confidence; and $0.81-1.00$, full confidence.

The quantitative parameters of the iodine map with statistical significance were drawn as the receiver-operating characteristic (ROC) curves, and the area under the curve (AUC) was used to evaluate the diagnostic efficacy of NIC of the diseased intestinal walls. The value of AUC ranged from 0.5 to 1.0 , which was considered as a poorly approached truth at 0.5 and a perfectly approached truth at 1.0. However, the ROC curves were without any predictive significance when the AUC was 0.5. We further calculated the specificity, sensitivity, and optimal threshold for a differential diagnosis of the activity of the intestinal walls.

\section{Statistical analysis}

All data were processed using SPSS 22.0 (IBM) statistical software. A Kolmogorv-Smirnov test was used to analyze the normal distribution of the data. The mean \pm SD was used for data with a normal distribution, which was compared using a one-way ANOVA among groups, and was multiply compared using a Tukey test among every two groups. The data without a normal distribution (such as the CT value, SNR, and CNR) were expressed using the median \pm quartile interval, and compared using a nonparametric Kruskal Wallis $\mathrm{H}$ test among groups, with a multiple pairwise comparison conducted among every two groups. The frequencies of the rating scales according to different physicians were compared using a paired $\chi 2$ test. A $P$ value of $<0.05$ was considered to be statistically significant.

\section{Results \\ Screening of the optimized VMI energy level Baseline of patients}

A total of 72 patients (40 male and 32 female) with negative CTE were enrolled for investigation of the optimized $\mathrm{keV}$ of VMI in DECTE. The patients were 19 to 76 years old with a mean age of $41.89 \pm 17.28$. Clinical baselines of 72 patients with negative CTE is shown in Additional file 5: Table S4.

\section{Objective and subjective imaging evaluations showed the best results at $60 \mathrm{keV}$}

The objective and subjective imaging evaluations of SMA are shown in Table 1. The objective imaging evaluation of SMA revealed that there were no significant differences in CNR and SNR between $60 \mathrm{keV}$ group and 40 or $50 \mathrm{keV}$ groups. Moreover, the CT value, CNR, and SNR of SMA at $60 \mathrm{keV}$ were higher than that at the $70-90 \mathrm{keV}$ groups. Subjective evaluation of SMA also showed that there was no significant difference in the number of branching vessels and imaging sharpness between 60 and $40 \mathrm{keV}$ or $50 \mathrm{keV}$ groups. Notably, the number of branching vessels and imaging sharpness in the $60 \mathrm{keV}$ group were higher than those in both the $70-90 \mathrm{keV}$ and $120 \mathrm{kVp}$ groups $(P<0.001)$. Among these groups, the $60 \mathrm{keV}$ group showed the best overall imaging quality with a significant difference $(P<0.05)$.

The objective and subjective imaging evaluations of small intestinal wall are shown in Table 2. Similarly, the objective evaluation of small intestinal wall, the $C T$ value, 
Table 1 Comparisons of subjective and objective evaluation parameters of SMA during arterial phase

\begin{tabular}{|c|c|c|c|c|c|c|}
\hline \multirow[t]{2}{*}{ Group } & \multicolumn{3}{|c|}{ Objective evaluation parameters } & \multicolumn{3}{|c|}{ Subjective evaluation parameters } \\
\hline & CT value & CNR & SNR & $\begin{array}{l}\text { Number of vascular } \\
\text { branches * }\end{array}$ & $\begin{array}{l}\text { Overall image } \\
\text { quality score }\end{array}$ & $\begin{array}{l}\text { Image } \\
\text { sharpness } \\
\text { score* }\end{array}$ \\
\hline $40 \mathrm{keV}$ & $1254.75 \pm 235.47^{\mathrm{a}}$ & $41.26 \pm 14.62^{\mathrm{a}}$ & $21.36 \pm 7.14^{b}$ & $4.17 \pm 0.81^{\mathrm{a}}$ & $4.29 \pm 0.32^{b}$ & $4.92 \pm 0.28^{\mathrm{a}}$ \\
\hline $50 \mathrm{keV}$ & $831.33 \pm 155.31^{b}$ & $37.18 \pm 13.21^{\mathrm{a}}$ & $21.20 \pm 7.11^{b}$ & $4.14 \pm 0.79^{a}$ & $4.34 \pm 0 . .23^{b}$ & $4.91 \pm 0 . .23^{\mathrm{a}}$ \\
\hline $60 \mathrm{keV}$ & $578.83 \pm 105.95^{c}$ & $33.05 \pm 12.22^{\mathrm{a}}$ & $21.16 \pm 7.29^{b}$ & $4.11 \pm 0.78^{\mathrm{a}}$ & $4.97 \pm 0.20^{\mathrm{a}}$ & $4.81 \pm 0.23^{\mathrm{a}}$ \\
\hline $70 \mathrm{keV}$ & $421.19 \pm 76.74^{c}$ & $28.5 \pm 10.84^{b}$ & $20.92 \pm 71.17^{b}$ & $3.38 \pm 0.49^{b}$ & $4.12 \pm 0.18^{b}$ & $4.14 \pm 0.35^{b}$ \\
\hline $80 \mathrm{keV}$ & $323.64 \pm 63.03^{d}$ & $24.89 \pm 9.78^{b c}$ & $19.03 \pm 7.03^{b}$ & $3.33 \pm 0.53^{b}$ & $4.03 \pm 0.17^{c}$ & $3.98 \pm 0.38^{b c}$ \\
\hline $90 \mathrm{keV}$ & $249.22 \pm 46.48^{d}$ & $18.45 \pm 7.23^{c}$ & $14.92 \pm 6.00^{c}$ & $2.36 \pm 0.48^{c}$ & $4.06 \pm 0.23^{c}$ & $3.03 \pm 0.17^{c}$ \\
\hline $120 \mathrm{kVp}$ & $431.81 \pm 105.84^{c}$ & $21.74 \pm 7.43^{c}$ & $26.55 \pm 10.15^{a}$ & $3.36 \pm 0.18^{b}$ & $4.08 \pm 0.19^{b c}$ & $4.03 \pm 0.29^{b}$ \\
\hline Z/F value & 235.641 & 200.304 & 163.572 & 7.574 & 7.424 & 7.311 \\
\hline$P$ value & $<0.001$ & $<0.001$ & $<0.001$ & 0.817 & 0.828 & 0.716 \\
\hline
\end{tabular}

"a, c, b, d" were multiple comparison marks. When marked with the same letter, it meant no significant difference between the two groups. When marked with different letters, it indicates the difference with statistically significant between the two groups. ${ }^{*}$ subjective scores were expressed as mean \pm standard deviation. $\mathrm{CT}$ : computed tomography; SMA: superior mesenteric artery; CNR: contrast-to-noise-ratio; SNR: signal-to-noise-ratio

Table 2 Comparisons of subjective and objective evaluation parameters of small intestinal wall during small intestine stage

\begin{tabular}{|c|c|c|c|c|c|c|}
\hline \multirow[t]{2}{*}{ Group } & \multicolumn{3}{|c|}{ Objective evaluation parameters } & \multicolumn{3}{|c|}{ Subjective evaluation parameters } \\
\hline & CT value & CNR & SNR & noise $^{*}$ & $\begin{array}{l}\text { Overall imaging } \\
\text { quality score* }\end{array}$ & $\begin{array}{l}\text { Imaging } \\
\text { sharpness } \\
\text { score* }\end{array}$ \\
\hline $40 \mathrm{keV}$ & $149.44 \pm 45.86^{\mathrm{a}}$ & $3.18 \pm 1.71^{\mathrm{a}}$ & $5.08 \pm 2.77^{\mathrm{a}}$ & $4.76 \pm 0.38^{\mathrm{a}}$ & $4.57 \pm 0.26^{b}$ & $4.91 \pm 0.37^{\mathrm{a}}$ \\
\hline $50 \mathrm{keV}$ & $108.24 \pm 31.03^{b}$ & $2.91 \pm 1.45^{\mathrm{a}}$ & $5.06 \pm 2.54^{\mathrm{a}}$ & $4.53 \pm 0.71^{\mathrm{a}}$ & $4.64 \pm 0.23^{b}$ & $4.84 \pm 0 . .53^{\mathrm{a}}$ \\
\hline $60 \mathrm{keV}$ & $83.24 \pm 22.45^{b}$ & $2.74 \pm 1.24^{\mathrm{a}}$ & $4.93 \pm 2.46^{a}$ & $4.38 \pm 0.59^{\mathrm{a}}$ & $4.91 \pm 0.61^{\mathrm{a}}$ & $4.27 \pm 0.97^{\mathrm{a}}$ \\
\hline $70 \mathrm{keV}$ & $67.79 \pm 17.47^{c}$ & $2.54 \pm 1.14^{\mathrm{b}}$ & $4.83 \pm 2.14^{b}$ & $4.11 \pm 0.78^{b}$ & $4.51 \pm 0.37^{b}$ & $4.12 \pm 0.68^{b}$ \\
\hline $80 \mathrm{keV}$ & $57.59 \pm 14.18^{\mathrm{cd}}$ & $1.89 \pm 1.05^{c}$ & $4.73 \pm 2.17^{b}$ & $3.36 \pm 0.85^{c}$ & $3.88 \pm 0.28^{c}$ & $3.43 \pm 0.27^{c}$ \\
\hline $90 \mathrm{keV}$ & $51.15 \pm 12.22^{d}$ & $1.52 \pm 0.95^{c}$ & $4.52 \pm 1.49^{c}$ & $3.17 \pm 0.41^{c}$ & $3.73 \pm 0.37^{c}$ & $3.06 \pm 0.23^{c}$ \\
\hline 120 kVp & $61.18 \pm 14.94^{c}$ & $2.74 \pm 1.33^{b}$ & $4.55 \pm 1.15^{c}$ & $3.96 \pm 0.48^{b}$ & $4.13 \pm 0.33^{b}$ & $4.28 \pm 0.29^{a}$ \\
\hline Z/F value & 185.041 & 98.104 & 82.172 & 5.164 & 5.221 & 5.111 \\
\hline$P$ value & $<0.001$ & $<0.001$ & $<0.001$ & 0.627 & 0.618 & 0.726 \\
\hline
\end{tabular}

"a, c, b, d" were multiple comparison marks. When marked with the same letter, it meant no significant difference between the two groups. When marked with different letters, it indicates the difference with statistically significant between the two groups. * subjective scores were expressed as mean \pm standard deviation. CT: computed tomography; CNR: contrast-to-noise-ratio; SNR: signal-to-noise-ratio

CNR, and SNR of the intestinal wall at $60 \mathrm{keV}$ was significantly higher than that at $70-90 \mathrm{keV}$ level $(P<0.05)$. For the subjective evaluation of small intestinal wall, the imaging noise, overall imaging quality, and sharpness scores at $60 \mathrm{keV}$ were higher than those at $70-90 \mathrm{keV}$.

Collectively, objective and subjective imaging evaluations showed the best results at $60 \mathrm{keV}$.

\section{Consistency of subjective imaging evaluations using two observers}

The consistency analysis of the subjective evaluation parameters of the images between patients with and without $C D$ indicated that the ICC of the imaging quality was consistent by two observers $(\mathrm{ICC}=0.82)$ as well as the ICC of the branches of vessels and the imaging sharpness (ICC $=0.76$ and 0.80 , respectively). Significant differences were found in the rating scales of the small intestinal wall and the branching vessels $(P<0.001)$ with mid-level ICC values (ICC $=0.51$ and 0.59 , respectively) (Additional file 5: Table S5).

\section{Analysis the diagnostic efficiency of DECTE iodine map and routine $C T E$ for $C D$}

\section{Baseline of patients}

A total of 68 patients (45 males and 23 females) with a mean age of $38.27 \pm 15.10$ years were included for an evaluation of the diagnostic efficacy of DECTE iodine map at the optimized VMI energy level combined with routine CTE. There were 35 patients with an onset of 
abdominal pain verified without any intestinal lesions through a clinical close follow-up (24 males and 11 females). The age of these 35 patients ranged from 18 to 65 years and the median was 35 . The other 33 patients

Table 3 Clinical baselines of 33 patients

\begin{tabular}{ll}
\hline Parameters & Contents \\
\hline Ages & The age ranged from 16 to \\
& 55 years old with a median of \\
& 27 years old \\
Gender (female: male) & $12: 21$ \\
Treatment & 10 cases were treated by \\
& internal medicine and 23 \\
& cases were not treated \\
Involvement of the intestinal segment & Jejunum and ileum: 8 \\
(cases) & \\
& Ileocecal: 25 \\
& Colon: 15 \\
& All involved: 15 \\
Degree of activity (cases) & Active stage: 18 \\
Mean of CRP & Remission stage: 15 \\
\hline
\end{tabular}

were clinically or pathologically diagnosed as having CD (21 males and 12 females). The age of these 33 patients ranged from 16 to 55 years and the median was 27 . Among the 33 patients with $\mathrm{CD}, 30$ patients received the first clinical visit and endoscopic examination, and 10 patients received medical treatment before CTE examination. Finally, according to the clinical comprehensive evaluation, 18 of the 33 patients were in an active stage and 15 patients were in a remission stage. All lesions were involved in the intestinal wall of these patients (Table 3).

\section{Consistency of subjective imaging evaluations using two observers}

The eight imaging characteristics of $C D$ are shown in Fig. 1. The consistency evaluation of imaging characteristics of $\mathrm{CD}$ by the two observers showed that the range of ICC was 0.78-1.00, indicating the high consistency. In another consistency evaluation of the diagnosis of CD conducted by the two observers, different opinions for three cases under routine CTE at $120 \mathrm{kVp}+\mathrm{VMI}$ at $60 \mathrm{keV}$, and four cases under routine CTE at $120 \mathrm{kVp}$, were elicited. The ICC of the two observers using different detections were 0.91 (95\% CI, 0.49-0.90) and 0.88
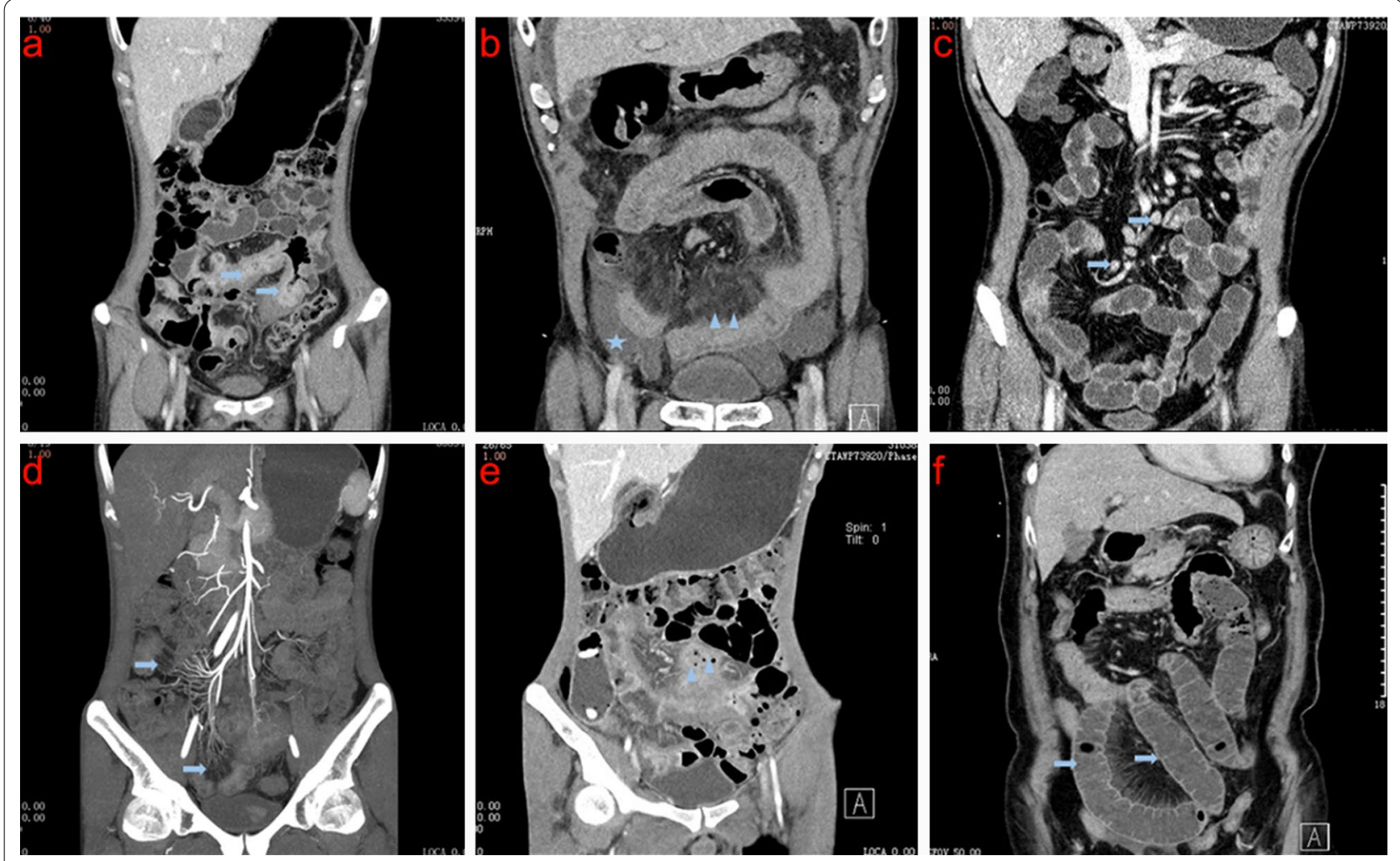

Fig. 1 CTE signs and images of CD. a Intestinal wall thickening (arrow), b mesenteric exudation (arrow) and peritoneal effusion (pentagram), c MLN enlargement (arrow), $\mathbf{d}$ proliferation of straight small vessels and "ulnar comb sign" (arrow), e fistula forming abdominal abscess (arrow), and $\mathbf{f}$ secondary intestinal obstruction of CD (arrow) 
(95\% CI, 0.70-0.95), respectively, suggesting that the final diagnosis given by both observers was consistent. Finally, we also conducted a consistency evaluation of $\mathrm{CD}$ activity under a routine CTE at $120 \mathrm{kVp}+\mathrm{VMI}$ at $60 \mathrm{keV}$ and a routine CTE at $120 \mathrm{kVp}$, and found that the ICC was 0.82 (95\% CI, 0.80-1.00) and 0.76 (95\% CI, 0.37-0.79), respectively, with different opinions for three and four cases (Table 4).

\section{Comparisons of diseased intestinal wall images in $C D$ during the small intestinal phase of CTE}

To visualize the clinical application of DECTE for CD diagnosis, the intestinal wall images of a $C D$ patient at routine CTE at $120 \mathrm{kVp}$ and routine CTE at 120 $\mathrm{kVp}+\mathrm{VMI}$ at $60 \mathrm{keV}$ are shown in Fig. 2. According to the diseased or normal small intestine, the patients were divided into $C D$ and normal groups. The patients in the
CD group were further divided into a remission subgroup and an active subgroup based on the $\mathrm{CD}$ activity. The differences in the quantitative characteristics of the intestinal segment, including the CT value (routine CTE at $120 \mathrm{kVp}$ or VMI at $60 \mathrm{keV}$ ), NIC, iodine value, and fat value, were compared between the $\mathrm{CD}$ (remission and active groups) and normal groups.

For a quantitative characteristic of CTE, the CT values of the normal group, active subgroup, and $C D$ group during the small intestinal phase at routine $120 \mathrm{kVp}$ or $60 \mathrm{keV}$ VMI had significant differences $(P<0.001)$. Among the parameters of the iodine map, the NIC and fat value in the $C D$ group were higher than those of the normal group $(P<0.001)$, and the parameters of the iodine map in the active group were higher than the remission group $(P<0.001)$ (Table 5$)$.

Table 4 Consistency of imaging characteristics, diagnosis of CD and activity of CD between the two observers

\begin{tabular}{|c|c|c|c|c|c|c|c|c|}
\hline & \multicolumn{4}{|c|}{ Regular CTE at $120 \mathrm{kVp}+\mathrm{VMI}$ at $60 \mathrm{keV}$} & \multicolumn{4}{|c|}{ Regular CTE at $120 \mathrm{kVp}$} \\
\hline & \multirow[t]{2}{*}{ Doctor B } & \multicolumn{2}{|c|}{ Doctor A } & \multirow{2}{*}{$\begin{array}{l}\text { ICC value } \\
(95 \% \mathrm{Cl})\end{array}$} & \multirow[t]{2}{*}{ Doctor B } & \multicolumn{2}{|c|}{ Doctor A } & \multirow{2}{*}{$\begin{array}{l}\text { ICC value } \\
(95 \% \mathrm{CI})\end{array}$} \\
\hline & & Yes & No & & & Yes & No & \\
\hline \multirow[t]{2}{*}{ Intestinal wall thickening } & Yes & 33 & 0 & $\begin{array}{l}1.000 \\
(0.63-0.91)\end{array}$ & Yes & 33 & 0 & $\begin{array}{l}1.000 \\
(0.42-0.86)\end{array}$ \\
\hline & No & 0 & 0 & & No & 0 & 0 & \\
\hline \multirow[t]{2}{*}{ Intestinal wall enhancement } & Yes & 28 & 3 & $\begin{array}{l}0.900 \\
(0.440 .081)\end{array}$ & Yes & 30 & 0 & $\begin{array}{l}0.783 \\
(0.37-0.71)\end{array}$ \\
\hline & No & 0 & 5 & & No & 1 & 3 & \\
\hline \multirow[t]{2}{*}{ Mesenteric lymph node enlargement } & Yes & 23 & 10 & $\begin{array}{l}0.821 \\
(0.70-0.98)\end{array}$ & Yes & 21 & 0 & $\begin{array}{l}0.866 \\
(0.61-0.88)\end{array}$ \\
\hline & No & 0 & 10 & & No & 1 & 12 & \\
\hline \multirow[t]{2}{*}{ Mesenteric exudation } & Yes & 30 & 0 & $\begin{array}{l}1.000 \\
(0.80-1.0)\end{array}$ & Yes & 29 & 0 & $\begin{array}{l}1.000 \\
(0.56-0.80)\end{array}$ \\
\hline & No & 0 & 3 & & No & 0 & 4 & \\
\hline \multirow[t]{2}{*}{ Straight small vessel proliferation } & Yes & 28 & 0 & $\begin{array}{l}1.000 \\
(0.50-0.91)\end{array}$ & Yes & 27 & 0 & $\begin{array}{l}0.886 \\
(0.62-0.99)\end{array}$ \\
\hline & No & 0 & 4 & & No & 1 & 6 & \\
\hline \multirow[t]{2}{*}{ Combined intestinal obstruction } & Yes & 2 & 0 & $\begin{array}{l}1.000 \\
(0.35-1.0)\end{array}$ & Yes & 1 & 0 & $\begin{array}{l}1.000 \\
(0.49-0.72)\end{array}$ \\
\hline & No & 0 & 31 & & No & 0 & 32 & \\
\hline \multirow[t]{2}{*}{ Fistula } & Yes & 1 & 0 & $\begin{array}{l}1.000 \\
(0.65-0.88)\end{array}$ & Yes & 1 & 0 & $\begin{array}{l}1.000 \\
(0.70-1.0)\end{array}$ \\
\hline & No & 0 & 32 & & No & 0 & 32 & \\
\hline \multirow[t]{2}{*}{ Ascites } & Yes & 3 & 0 & $\begin{array}{l}1.000 \\
(0.80-1.0)\end{array}$ & Yes & 2 & 0 & $\begin{array}{l}1.000 \\
(0.38-0.88)\end{array}$ \\
\hline & No & 0 & 30 & & No & 0 & 31 & \\
\hline \multirow[t]{2}{*}{ Diagnosis of CD } & Yes & 28 & 2 & $\begin{array}{l}0.91 \\
(0.49-0.90)\end{array}$ & Yes & 31 & 2 & $\begin{array}{l}0.88 \\
(0.70-0.95)\end{array}$ \\
\hline & No & 1 & 37 & & No & 2 & 33 & \\
\hline \multirow[t]{2}{*}{ Activity of CD } & Yes & 16 & 2 & $\begin{array}{l}0.82 \\
(0.80-1)\end{array}$ & Yes & 15 & 2 & $\begin{array}{l}0.76 \\
(0.37-0.79)\end{array}$ \\
\hline & No & 1 & 14 & & No & 2 & 14 & \\
\hline
\end{tabular}



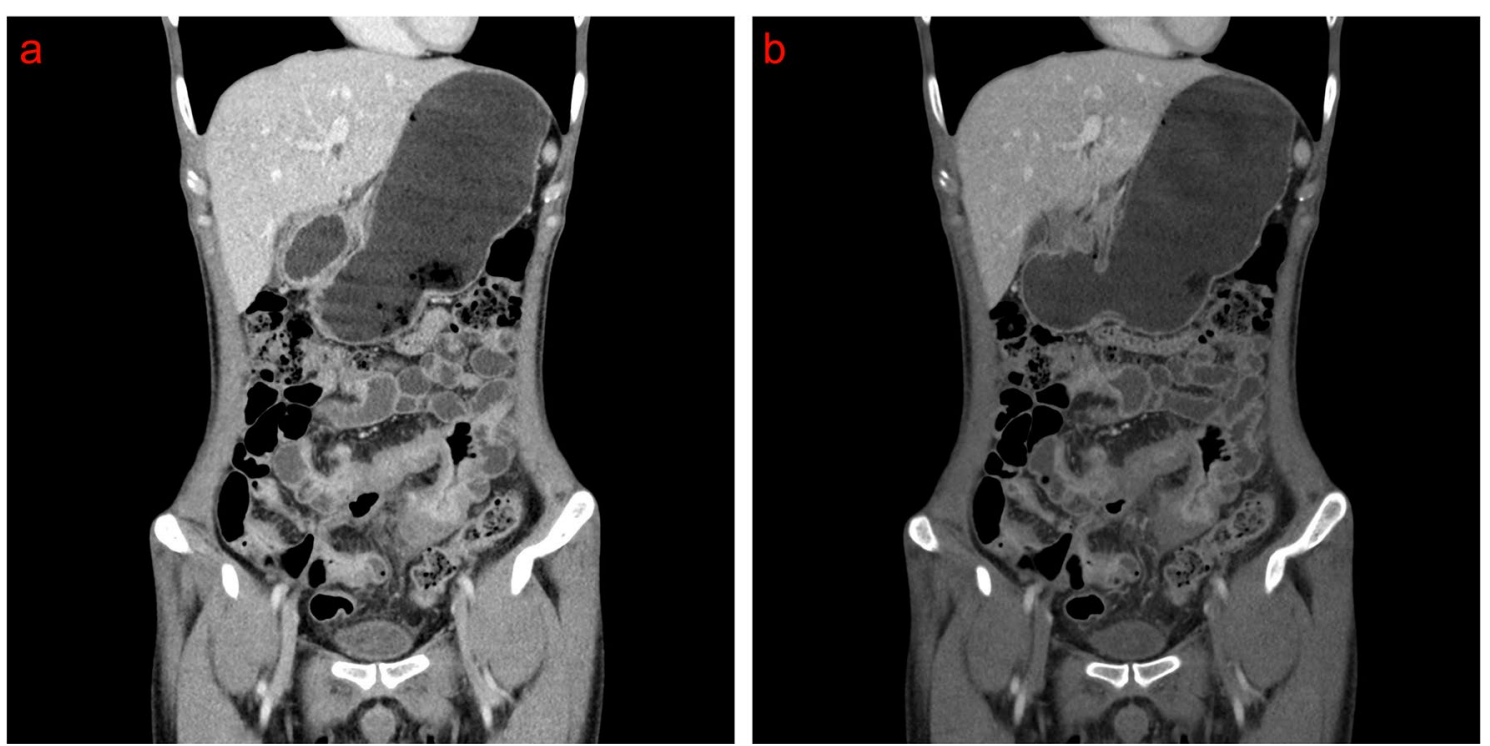

Fig. 2 The intestinal wall images of a 36-year-old male CD patient at routine CTE at $120 \mathrm{kVp}$ and routine CTE at $120 \mathrm{kVp}+\mathrm{VMl}$ at $60 \mathrm{keV}$. a Image at routine CTE at $120 \mathrm{kVp}$, b Image at routine CTE at $120 \mathrm{kVp}+\mathrm{VMl}$ at $60 \mathrm{keV}$

Table 5 Comparisons of parameters between different stage of diseased and normal intestinal wall images during the small intestinal phase of CTE

\begin{tabular}{lccrrr}
\hline & Normal group & $\begin{array}{l}\text { CD group (active } \\
\text { subgroup) }\end{array}$ & $\begin{array}{l}\text { CD group (remission } \\
\text { subgroup) }\end{array}$ & Z/F value & $P$ value \\
\hline CT value (120 kVp) & $51.28 \pm 12.84$ & $97.50 \pm 40.29^{\mathrm{a}}$ & $77.46 \pm 14.51^{\mathrm{b}}$ & 32.38 & 0.017 \\
CT value (VMl at 60 keV) & $83.57 \pm 11.45$ & $103.61 \pm 18.12^{\mathrm{a}}$ & $88.69 \pm 22.43^{\mathrm{b}}$ & 28.79 & 342.58 \\
NIC & $24.22 \pm 10.16$ & $54.62 \pm 12.76^{\mathrm{a}}$ & $36.23 \pm 14.00^{\mathrm{b}}$ & $<012$ \\
lodine density & $3.21 \pm 2.39$ & $6.31 \pm 1.85^{\mathrm{a}}$ & $4.78 \pm 1.48^{\mathrm{b}}$ & 136.47 & $<001$ \\
Fat fraction & $35.38 \pm 23.03$ & $69.34 \pm 17.24^{\mathrm{a}}$ & $56.77 \pm 13.20^{\mathrm{b}}$ & 107.26 & $<0.001$ \\
\hline
\end{tabular}

"a, b" were multiple comparison marks. When marked with different letters, it indicates the difference with statistically significant between the two groups. CD: Crohn's disease; CT: computed tomography; CTE: computed tomography enterography; NIC: ormalized iodine concentration; VMI: virtual monoenergetic imaging

\section{Diagnostic efficacy of DECTE iodine map}

The ROC curve was used to analyze the diagnostic efficacy of NIC, and the fat value in the iodine map was evaluated by DECTE through a CD diagnosis (Fig. 3). There were 68 patients in this group, of which 33 were diagnosed with $\mathrm{CD}$ and 35 were normal. In the ROC curve, the maximum AUC was 0.89 when $\mathrm{NIC}<0.83(\mathrm{NIC}=4 \%)$ was used as the threshold. Thus, the best efficacy of the differential diagnosis was obtained with a specificity of $92.1 \%$ and a sensitivity of $90.9 \%$. When a fat value $<0.83$ (fat value $=45.8 \%$ ) was used as the threshold, the maximum AUC was 0.91, and thus the best efficacy of a differential diagnosis was obtained with a specificity of $92.1 \%$ and a sensitivity of $90.9 \%$ (Additional file 5: Table S6 and Fig. 4).

Using the ROC curve to analyze the diagnostic efficacy of the iodine map evaluated using DECTE for active
CD: There were $33 \mathrm{CD}$ patients, among which 18 were in an active stage and 15 in a remission stage. In the ROC curve, according to the maximum point of the Youden index as the threshold, the maximum AUC is 0.72 when $\mathrm{NIC}<0.35$ was used as the threshold, and thus the efficacy of the differential diagnosis was the best with a specificity of $50.0 \%$ and a sensitivity of $85.2 \%$. When a fat value $<0.38$ was used as the threshold, the maximum AUC was 0.59, and thus the efficacy of a differential diagnosis was the best with a specificity of $59.1 \%$ and a sensitivity of $80.0 \%$ (Additional file 5: Table S7).

\section{Diagnostic efficiency of VMI combined with routine CTE}

Among the 68 patients, 33 cases were comprehensively diagnosed with $\mathrm{CD}$ through endoscope and clinical symptoms. Two radiologists using routine CTE at 120 $\mathrm{kVp}+\mathrm{VMI} 60 \mathrm{keV}$ diagnosed CD as a true positive in 29 

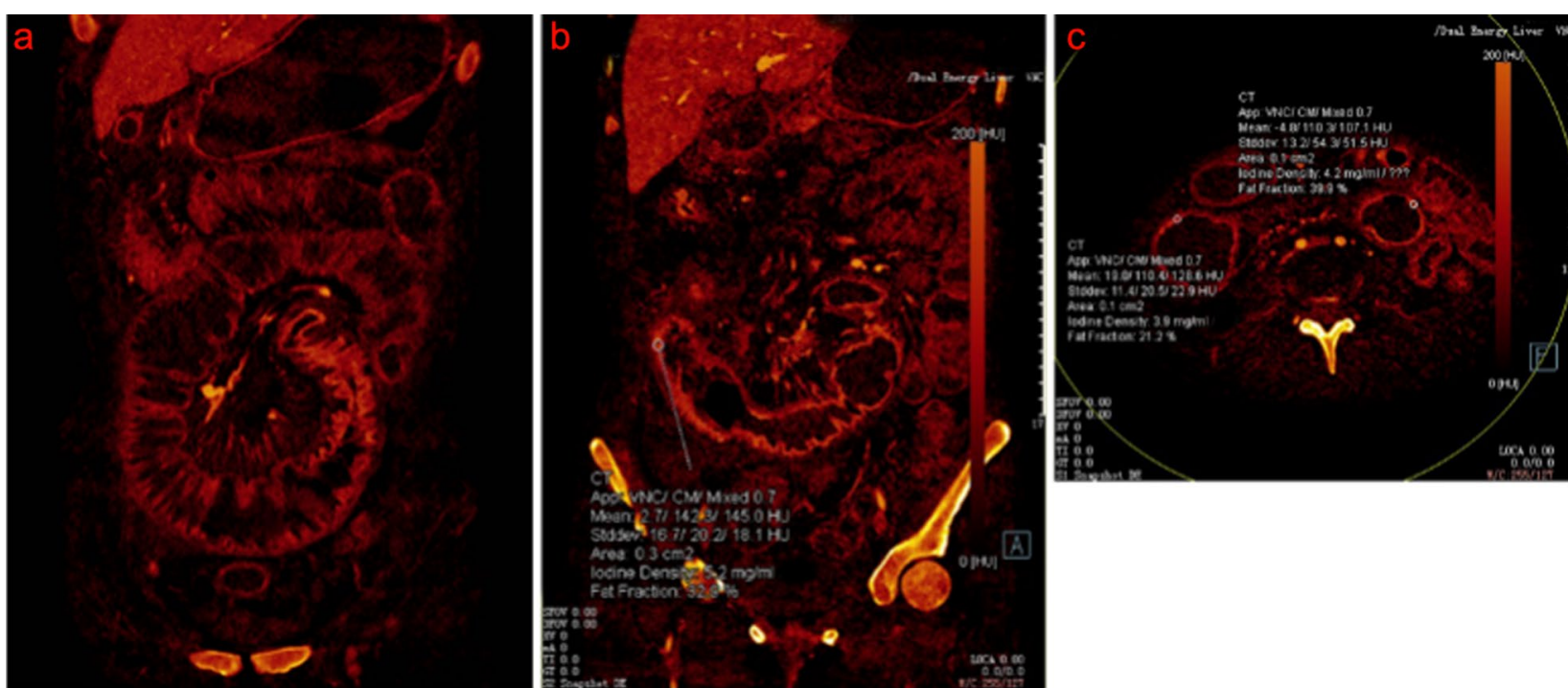

Fig. 3 Parameter measurement of lesion on iodine map in intestinal wall of CD. A 38-year-old female was diagnosed with CD by endoscopy and clinical diagnosis (active stage). $\mathbf{a}, \mathbf{b}$ the coronal position of the iodine map of the small intestine and $\mathbf{c}$ transverse position of the iodine map of the small intestine. $\mathbf{b}$ indicates that the ROI area was $0.3 \mathrm{~cm}^{2}$, the iodine value was $5.2 \mathrm{mg}$, the fat value was $32.9 \%$, the ROI area was $0.1 \mathrm{~cm}^{2}$, the iodine value was $3.9 \mathrm{mg} / \mathrm{ml}$, and the fat value was $21.2 \%$. ROl: region of interest

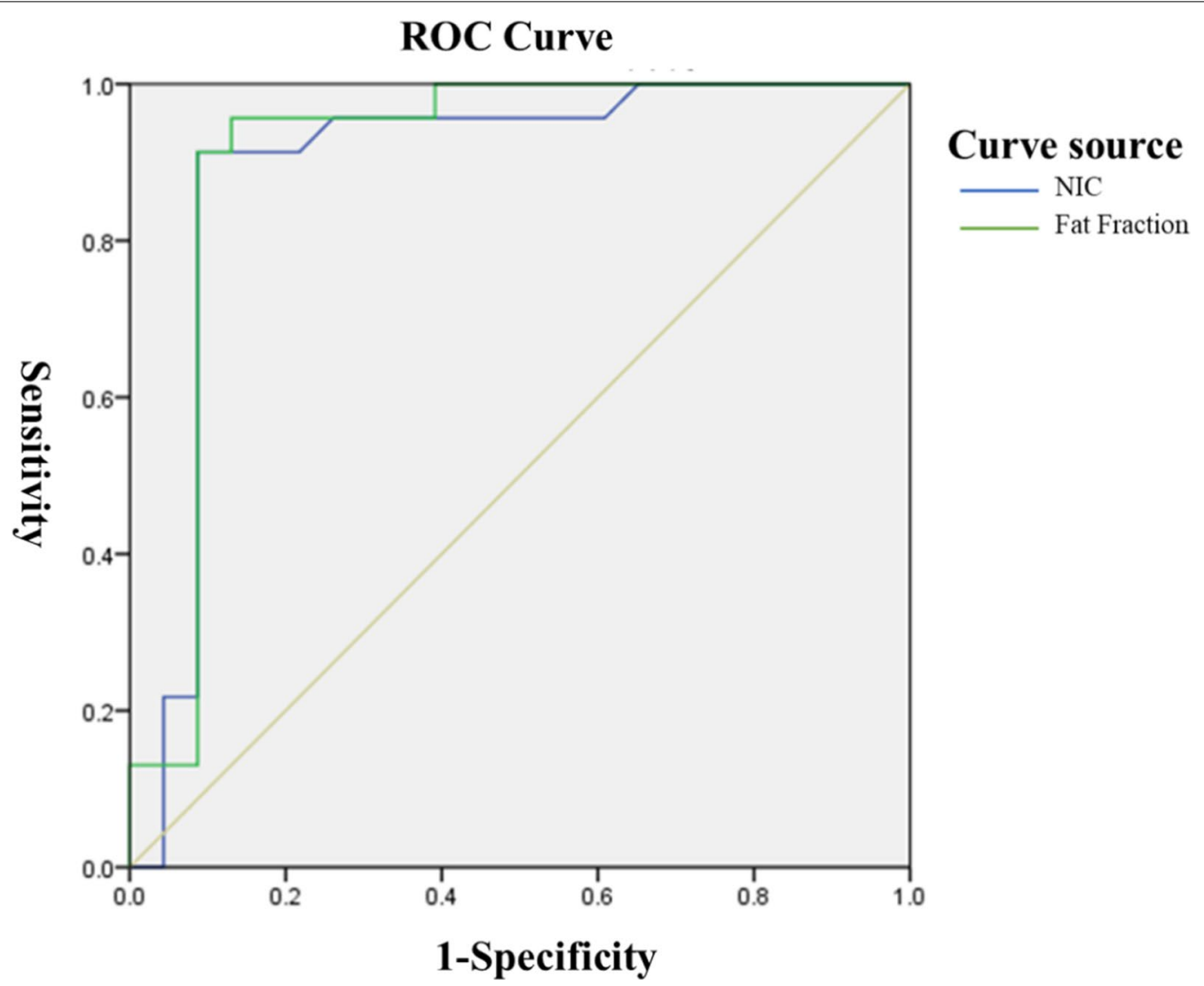

Fig. 4 ROC curve of standardized iodine value and fat value in intestinal wall during small intestinal phase in diagnosed CD. In the ROC curve, when $\mathrm{NIC}<0.83(\mathrm{NIC}=4 \%)$ was used as the threshold and the maximum AUC was 0.89 , the efficacy of differential diagnosis was the best. When a fat value of $<0.83$ (fat value $=45.8 \%$ ) was used as the threshold and the maximum AUC was 0.91 , the efficacy of a differential diagnosis was the best 
cases, as a false positive in 4 cases, as a true negative in 33 cases, and as a false negative in 2 cases. In comparison, routine CTE at $120 \mathrm{kVp}$ diagnosed $\mathrm{CD}$ as a true positive in 33 cases, false positive in 2 cases, true negative in 30 cases, and false negative in 5 cases. The sensitivity, specificity, positive predictive value, negative predictive value, and accuracy were 93.5\%, 89.2\%, 87.9\%, 94.3\% and 91.3\%, respectively. The comparison of the ROC curve showed that the combined tests improved the efficiency of CD diagnosis with an increasing AUC from 0.82 (routine CTE) to 0.88 (combined tests) with statistical significance $(P<0.001)$ (Additional file 5: Table S8 and Fig. 5).

\section{Discussion}

In the present study, we found that $60 \mathrm{keV}$ was the optimized energy level to quantify images using DECTE, and the diagnostic efficacy of CTE at a routine $120 \mathrm{kVp}$ linked with VMI at $60 \mathrm{keV}$ was significantly improved in the diagnosis of $C D$, as proved by the increase in AUC from 0.82 (routine CTE) to 0.88 (combined tests).

Through an infusion of the contrast medium, enhanced CT can offer more detailed information on the thickness and bloodstream of a disease intestine when compared with the adjacent normal intestine [27]. The decline and elevated signal of enhancement can help with a differential diagnosis with inflammatory, infection, and metastasis scenes [28]. The intestine condition can be assessed using $120 \mathrm{kVp}$ as a routine parameter, and CT attenuation is exhibited as white, gray, water halo, and black [29]. DECT is an innovative technique combined with enhanced CT and VMI, which aids in the reconstruction of a colorful or graded gray image at a lower energy level [30]. Moreover, an iodine map with a continuous enhancement of iodine is a practical tool to quantitatively measure the enhancement of the regions of interest in intestinal walls and to further provide evidence with strong confidence [29]. Iodine concentration, measured on detector-based DECTE, has been considered as a convenient and reproducible biomarker to detect disease activity in CD [11]. However, this process of quantification requires a skilled radiologist to select the appropriate threshold to determine the change in iodine concentration in a tissue, which is relevant with the diseased conditions of the intestine.

Anatomically, the branches of superior and inferior mesenteric artery supply the bloodstream of small intestine and form a circular branch of arcuate anastomosis in the mesentery. Wu et al. found that the degree of angiogenesis around the intestinal wall on the CTE was highly related to the activity of $\mathrm{CD}$ [31]. The small rectal vessels adjacent to the diseased intestinal wall proliferated

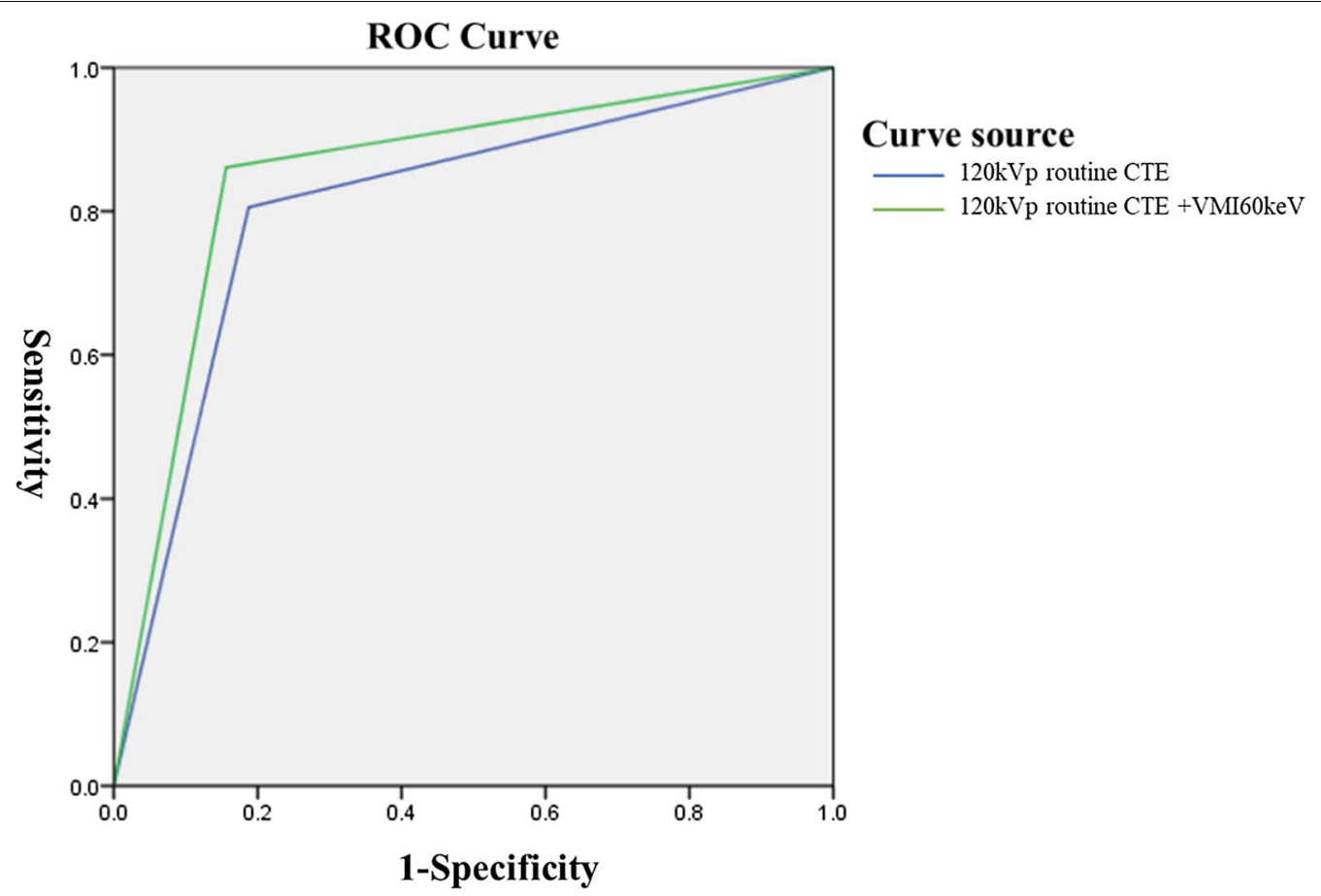

Fig. 5 Comparison of diagnostic efficacy between routine CTE at $120 \mathrm{kVp}+\mathrm{VMI}$ at $60 \mathrm{keV}$ and routine CTE at $120 \mathrm{kVp}$ in CD diagnosis. A comparison of the ROC curve showed that the combined tests improved the diagnostic efficiency of CD with an increase in the AUC from 0.82 (routine CTE at $120 \mathrm{kVp}$ ) to 0.88 (routine CTE at $120 \mathrm{kVp}+\mathrm{VMI}$ at $60 \mathrm{keV}$ ) with statistical significance $(P<0.001)$ 
and congested, showing the characteristic of a "comblike" structure. Since endoscopy can only show the inter surface of intestinal walls, it is impossible to explore the proliferation of vessels around the intestinal wall or the extra-intestinal diseases. Meanwhile, CTE, which is applied for a three-dimensional observation and is postprocessed to reconstruct the sagittal and coronal plane of the images, can solve the problems of endoscopy [32]. For the extra-intestinal complications, such as a blurred peri-intestinal fat space and mesenteric vascular hyperplasia, the sensitivity of CTE remains at $80 \%-100 \%$ with an obvious advantage in evaluating the condition and activity of CD [9].

Our results showed that CTE at $40-60 \mathrm{keV}$ can better display the SMA without clear differences in imaging quality, which is consistent with the published literature [33]. Some scholars state that a new single-energy spectrum technology can reduce the noise of a low-keV single-spectrum image more significantly with a higher CNR [19]. In our study, there were no significant differences in the objective evaluation parameters (CNR and SNR) between 60 and $40 \mathrm{keV}$ levels, and the overall imaging quality at $60 \mathrm{keV}$ were higher than in the other energy level groups. Therefore, after a comprehensive consideration, we consider $60 \mathrm{keV}$ to be the best energy level. Moreover, as $70 \mathrm{keV}$ images quite compare to $120 \mathrm{kVp}$, simply reducing the tube voltage in SECT scans to 100 or $80 \mathrm{kVp}$ may be an alternative to DECT.

Villanueva et al. found that the CTE measurement of the terminal ileum was closely related to the endoscopic results [34]. The enhancement of the intestinal wall on the CTE can predict the activity of CD inflammation with a high sensitivity of $90 \%$, which reaches $80 \%$ for a visual assessment [35]. As is well-known, active inflammation is linked with more blood perfusion and accompanying iodine concentration, and thus the iodine map on DECTE can clearly indicate the activity of CD [36]. However, the efficacy of the fat value in the assessment of CD activity is low in our study, which may be explained as the proliferation of fat caused by a long-term repeated injury of the intestinal wall under $C D$ conditions. Therefore, both NIC and the fat value should be practically considered in the diagnosis of $\mathrm{CD}$.

In this study, we innovatively compared patients with and without CD through DECTE and conducted a comprehensive clinical diagnosis to protect the subjects from high doses of radiation. We then utilized a VMI in CTE to subjectively evaluate the images at the best energy level, which was appropriate for displaying the intestinal walls and vessels simultaneously. In addition, we utilized the U-net model to semi-quantitatively determine the branches of the SMA, which transferred the subjective evaluation to the objective index. Finally, we demonstrated the value of DECTE in a CD diagnosis through the reference threshold of the iodine maps, and the value of the MIP reconstruction of the SMA (the thickness of the slice was $10.0 \mathrm{~mm}$ and interval between slices was $5.0 \mathrm{~mm}$ ) in the diagnosis of inflammatory vessel proliferation. However, there were some limitations to this study: (1) Evaluations in normal patients with multiple displays of normal intestine showed some deviation. (2) Subjective scores showed some bias for an evaluation of the intestinal wall. (3) The sample size of the CD patients was small, and subjective imaging evaluations were conducted by only two observers. Further studies with more participants and observers are needed to confirm our findings. (4) The concentration of iodine was influenced by the injection dose and patient status, requiring further evidence to verify these quantified data.

\section{Conclusion}

In conclusion, CTE at $120 \mathrm{kVp}$ linked with a VMI at $60 \mathrm{keV}$ can better display the intestinal wall and blood vessels simultaneously. Meanwhile, the DECTE and quantitative NIC parameters are valuable for the diagnosis and evaluation of activity in CD patients, respectively. Finally, the combined use of VMI at $60 \mathrm{keV}$ and conventional CTE at $120 \mathrm{kVp}$ can improve the efficiency of CD diagnosis.

\section{Supplementary Information}

The online version contains supplementary material available at https://doi. org/10.1186/s12880-021-00716-y.

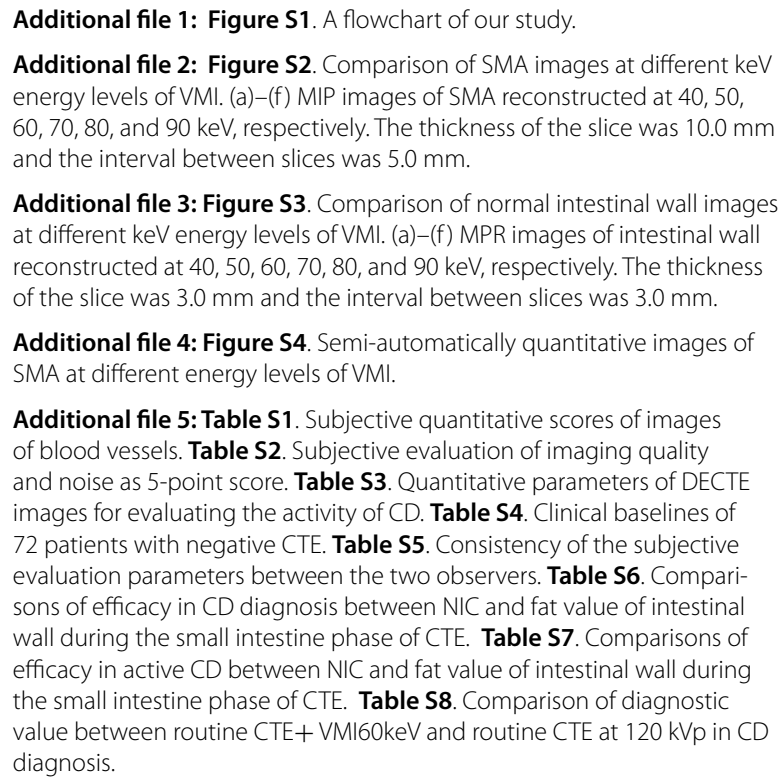
energy levels of VMI. (a)-(f) MIP images of SMA reconstructed at 40, 50, $60,70,80$, and $90 \mathrm{keV}$, respectively. The thickness of the slice was $10.0 \mathrm{~mm}$ and the interval between slices was $5.0 \mathrm{~mm}$.

Additional file 3: Figure S3. Comparison of normal intestinal wall images at different keV energy levels of VMI. (a)-(f) MPR images of intestinal wall reconstructed at 40,50,60,70,80, and $90 \mathrm{keV}$, respectively. The thickness of the slice was $3.0 \mathrm{~mm}$ and the interval between slices was $3.0 \mathrm{~mm}$.

Additional file 4: Figure S4. Semi-automatically quantitative images of SMA at different energy levels of VMI.

Additional file 5: Table S1. Subjective quantitative scores of images of blood vessels. Table S2. Subjective evaluation of imaging quality and noise as 5-point score. Table S3. Quantitative parameters of DECTE images for evaluating the activity of CD. Table S4. Clinical baselines of 72 patients with negative CTE. Table S5. Consistency of the subjective evaluation parameters between the two observers. Table S6. Comparisons of efficacy in CD diagnosis between NIC and fat value of intestinal wall during the small intestine phase of CTE. Table S7. Comparisons of efficacy in active CD between NIC and fat value of intestinal wall during the small intestine phase of CTE. Table S8. Comparison of diagnostic value between routine CTE + VMl60keV and routine CTE at $120 \mathrm{kVp}$ in CD diagnosis.

\section{Acknowledgements}

None. 


\section{Authors' contributions}

Conception and design of the research: $\mathrm{BSH}, \mathrm{JZ}$ and $\mathrm{JHC}$; acquisition of data: JSY and RCC; analysis and interpretation of data: JSY and RCC; statistical analysis: JJS and JX; obtaining funding: $\mathrm{BSH}$; drafting the manuscript: JZ and $J H C$; revision of manuscript for important intellectual content: Bosheng He. All authors read and approved the final manuscript.

\section{Funding}

This work was supported by the [Social Development Fund of Nantong] under Grant [number MS22019013, HS2019002]; [The Fifth Round of the "Programme 333" of Jiangsu] under Grant [number BRA2020198]; and [Young Medical Talents Fund of Health and Family Planning Commission of Nantong] under Grant [number WKZL2018017, QA2019008]

\section{Availability of data and materials}

The data used to support the findings of this study are available from the corresponding author upon request.

\section{Declarations}

\section{Ethics approva}

This study was approved by the Ethics Committee of Affiliated Hospital 2 of Nantong University (2019KW022) and the requirement to obtain informed written consent was waived. All methods were carried out in accordance with relevant guidelines and regulations.

\section{Consent for publication}

Not applicable.

\section{Competing interests}

The authors declare that they have no competing interests.

\section{Author details}

${ }^{1}$ Department of Radiology, Affiliated Hospital 2 of Nantong University, Nantong City 226001, Jiangsu Province, China. ${ }^{2}$ Department of Radiology, Changzhou Hospital of Traditional Chinese Medicine, Changzhou City 213000, Jiangsu Province, China. ${ }^{3}$ Gastrointestinal Surgery, Affiliated Hospital 2 of Nantong University, Nantong City 226001, Jiangsu Province, China. ${ }^{4}$ Department of Epidemiology and Medical Statistics, School of Public Health, Nantong University, Nantong City 226019, Jiangsu Province, China. ${ }^{5}$ Department of Biochemistry, Nantong University Medical School, Nantong City 226019, Jiangsu Province, China. ${ }^{6}$ Clinical Medicine Research Center, Affiliated Hospital 2 of Nantong University, Nantong City 226001, Jiangsu Province, China.

Received: 2 August 2021 Accepted: 15 November 2021

Published online: 03 December 2021

\section{References}

1. Torres J, Mehandru S, Colombel JF, Peyrin-Biroulet L. Crohn's disease. Lancet. 2017;389(10080):1741-55.

2. Ng SC, Shi HY, Hamidi N, Underwood FE, Tang W, Benchimol El, Panaccione R, Ghosh S, Wu JCY, Chan FKL, et al. Worldwide incidence and prevalence of inflammatory bowel disease in the 21st century: a systematic review of population-based studies. Lancet. 2018;390(10114):2769-78.

3. Li J, Mao R, Kurada S, Wang J, Lin S, Chandra J, Rieder F. Pathogenesis of fibrostenosing Crohn's disease. Transl Res. 2019;209:39-54.

4. Rimola J, Rodriguez S, García-Bosch O, Ordás I, Ayala E, Aceituno M, Pellisé M, Ayuso C, Ricart E, Donoso L, et al. Magnetic resonance for assessment of disease activity and severity in ileocolonic Crohn's disease. Gut. 2009;58(8):1113-20.

5. Qiu Y, Mao R, Chen BL, Li XH, He Y, Zeng ZR, Li ZP, Chen MH. Systematic review with meta-analysis: magnetic resonance enterography vs. computed tomography enterography for evaluating disease activity in small bowel Crohn's disease. Aliment Pharmacol Ther. 2014:40(2):134-46.

6. Masselli G, Di Tola M, Casciani E, Polettini E, Laghi F, Monti R, Bernieri MG, Gualdi G. Diagnosis of small-bowel diseases: prospective comparison of multi-detector row CT enterography with MR enterography. Radiology. 2016;279(2):420-31.
7. Taguchi N, Oda S, Kobayashi T, Naoe H, Sasaki Y, Imuta M, Nakaura T, Yamashita Y. Advanced parametric imaging for evaluation of Crohn's disease using dual-energy computed tomography enterography. Radiol Case Rep. 2018;13(3):709-12.

8. Akbas A, Bakir H, Dasiran MF, Dagmura H, Daldal E, Ozsoy Z, Ozmen Z, Demir O, Okan I. Colonic wall thickening reported in abdominal CT: does it always imply malignancy? Gastroenterol Res Pract. 2019;2019:2492097.

9. Bodily KD, Fletcher JG, Solem CA, Johnson CD, Fidler JL, Barlow JM, Bruesewitz MR, McCollough CH, Sandborn WJ, Loftus EV Jr, et al. Crohn disease: mural attenuation and thickness at contrast-enhanced CT enterography-correlation with endoscopic and histologic findings of inflammation. Radiology. 2006;238(2):505-16.

10. Sakurai T, Katsuno T, Saito K, Yoshihama S, Nakagawa T, Koseki H, Taida T, Ishigami H, Okimoto Kl, Maruoka D, et al. Mesenteric findings of CT enterography are well correlated with the endoscopic severity of Crohn's disease. Eur J Radiol. 2017:89:242-8.

11. Kim YS, Kim SH, Ryu HS, Han JK. lodine quantification on spectral detector-based dual-energy CT enterography: correlation with Crohn's disease activity index and external validation. Korean J Radiol. 2018;19(6):1077-88.

12. De Kock I, Delrue L, Lecluyse C, Hindryckx P, De Vos M, Villeirs G. Feasibility study using iodine quantification on dual-energy CT enterography to distinguish normal small bowel from active inflammatory Crohn's disease. Acta Radiol. 2019;60(6):679-86.

13. Dane B, Duenas S, Han J, O'Donnell T, Ream J, Chang S, Megibow A. Crohn's disease activity quantified by iodine density obtained from dualenergy computed tomography enterography. J Comput Assist Tomogr. 2020;44(2):242-7

14. Hanson GJ, Michalak GJ, Childs R, McCollough B, Kurup AN, Hough DM, Frye JM, Fidler JL, Venkatesh SK, Leng S, et al. Low kV versus dual-energy virtual monoenergetic CT imaging for proven liver lesions: what are the advantages and trade-offs in conspicuity and image quality? A pilot study. Abdom Radiol (NY). 2018:43(6):1404-12.

15. Sudarski S, Apfaltrer P, Nance JW Jr, Schneider D, Meyer M, Schoenberg SO, Fink C, Henzler T. Optimization of keV-settings in abdominal and lower extremity dual-source dual-energy CT angiography determined with virtual monoenergetic imaging. Eur J Radiol. 2013;82(10):e574-581

16. Kambadakone AR, Prakash P, Hahn PF, Sahani DV. Low-dose CT examinations in Crohn's disease: Impact on image quality, diagnostic performance, and radiation dose. AJR Am J Roentgenol. 2010;195(1):78-88.

17. Kielar AZ, Tao H, McKeever C, El-Maraghi RH. Low-radiation-dose modified small bowel CT for evaluation of recurrent Crohn's disease. Gastroenterol Res Pract. 2012;2012:598418.

18. Yeh BM, Obmann MM, Westphalen AC, Ohliger MA, Yee J, Sun Y, Wang ZJ. Dual energy computed tomography scans of the bowel: benefits, pitfalls, and future directions. Radiol Clin North Am. 2018;56(5):805-19.

19. Darras KE, McLaughlin PD, Kang H, Black B, Walshe T, Chang SD, Harris AC, Nicolaou S. Virtual monoenergetic reconstruction of contrast-enhanced dual energy $C T$ at 70keV maximizes mural enhancement in acute small bowel obstruction. Eur J Radiol. 2016;85(5):950-6.

20. He B, Gong S, Hu C, Fan J, Qian J, Huang S, Cui L, Ji Y. Obscure gastrointestinal bleeding: diagnostic performance of 64-section multiphase CT enterography and CT angiography compared with capsule endoscopy. $\mathrm{Br}$ J Radiol. 2014;87(1043):24.

21. Miao F. Intestinal imaging. Shanghai: Shanghai Science and Technology Press; 2013.

22. Beeres M, Trommer J, Frellesen C, Nour-Eldin NE, Scholtz JE, Herrmann E, VogITJ, Wichmann JL. Evaluation of different keV-settings in dual-energy CT angiography of the aorta using advanced image-based virtual monoenergetic imaging. Int J Cardiovasc Imaging. 2016;32(1):137-44.

23. Booya F, Fletcher JG, Huprich JE, Barlow JM, Johnson CD, Fidler JL, Solem CA, Sandborn WJ, Loftus EV Jr, Harmsen WS. Active Crohn disease: CT findings and interobserver agreement for enteric phase CT enterography. Radiology. 2006;241(3):787-95.

24. Liu Y, Tao X, Jia L, Cheng KW, Lu Y, Yu Y, Feng Y. Knockdown of RAB25 promotes autophagy and inhibits cell growth in ovarian cancer cells. Mol Med Rep. 2012;6(5):1006-12.

25. You JY. Features and management of very early onset inflammatory bowel disease. Zhongguo Dang Dai Er Ke Za Zhi. 2018;20(5):341-5.

26. Bruining DH, Zimmermann EM, Loftus EV Jr, Sandborn WJ, Sauer CG, Strong SA. Consensus recommendations for evaluation, interpretation, 
and utilization of computed tomography and magnetic resonance enterography in patients with small bowel Crohn's disease. Radiology. 2018;286(3):776-99.

27. Macari M, Balthazar EJ. CT of bowel wall thickening: significance and pitfalls of interpretation. AJR Am J Roentgenol. 2001;176(5):1105-16

28. Meier A, Wurnig M, Desbiolles L, Leschka S, Frauenfelder T, Alkadhi H. Advanced virtual monoenergetic images: improving the contrast of dualenergy CT pulmonary angiography. Clin Radiol. 2015;70(11):1244-51.

29. Fulwadhva UP, Wortman JR, Sodickson AD. Use of dual-energy CT and iodine maps in evaluation of bowel disease. Radiographics. 2016;36(2):393-406

30. Potretzke TA, Brace CL, Lubner MG, Sampson LA, Willey BJ, Lee FT Jr. Early small-bowel ischemia: dual-energy CT improves conspicuity compared with conventional CT in a swine model. Radiology. 2015;275(1):119-26.

31. Wu YW, Tang YH, Hao NX, Tang CY, Miao F. Crohn's disease: CT enterography manifestations before and after treatment. Eur J Radiol. 2012:81(1):52-9

32. Saade C, Nasr L, Sharara A, Barada K, Soweid A, Murad F, Tawil A, Ghieh D, Asmar K, Tamim H, et al. Crohn's disease: a retrospective analysis between computed tomography enterography, colonoscopy, and histopathology. Radiography (Lond). 2019;25(4):349-58.

33. Lee SM, Kim SH, Ahn SJ, Kang HJ, Kang JH, Han JK. Virtual monoenergetic dual-layer, dual-energy CT enterography: optimization of keV settings and its added value for Crohn's disease. Eur Radiol. 2018;28(6):2525-34.

34. Villanueva Campos AM, Tardáguila de la Fuente G, Utrera Pérez E, Jurado Basildo C, Mera Fernández D, Martínez Rodríguez C. Value of dual-energy $\mathrm{CT}$ enterography in the analysis of pathological bowel segments in patients with Crohn's disease. Radiologia. 2018;60(3):223-9.

35. Sun K, Han R, Han Y, Shi X, Hu J, Lu B. Accuracy of combined computed tomography colonography and dual energy iiodine map imaging for detecting colorectal masses using high-pitch dual-source CT. Sci Rep. 2018:8(1):3790

36. Peng JC, Feng Q, Zhu J, Shen J, Qiao YQ, Xu JR, Ran ZH. Usefulness of spectral computed tomography for evaluation of intestinal activity and severity in ileocolonic Crohn's disease. Therap Adv Gastroenterol. 2016;9(6):795-805.

\section{Publisher's Note}

Springer Nature remains neutral with regard to jurisdictional claims in published maps and institutional affiliations.

Ready to submit your research? Choose BMC and benefit from:

- fast, convenient online submission

- thorough peer review by experienced researchers in your field

- rapid publication on acceptance

- support for research data, including large and complex data types

- gold Open Access which fosters wider collaboration and increased citations

- maximum visibility for your research: over $100 \mathrm{M}$ website views per year

At BMC, research is always in progress.

Learn more biomedcentral.com/submissions 